\title{
Transculturalization of a Diabetes-Specific Nutrition Algorithm: Asian Application
}

\author{
Hsiu-Yueh Su • Man-Wo Tsang • Shih-Yi Huang • \\ Jeffrey I. Mechanick • Wayne H-H. Sheu • \\ Albert Marchetti • \\ on behalf of the Task Force for Development of \\ Transcultural Algorithms in Nutrition and Diabetes
}

Published online: 5 February 2012

(C) Springer Science+Business Media, LLC 2012

\begin{abstract}
The prevalence of type 2 diabetes (T2D) in Asia is growing at an alarming rate, posing significant clinical and economic risk to health care stakeholders. Commonly, Asian patients with T2D manifest a distinctive combination of characteristics that include earlier disease onset, distinct pathophysiology, syndrome of complications, and shorter life expectancy. Optimizing treatment outcomes for such patients requires a coordinated inclusive care plan and knowledgeable practitioners. Comprehensive management starts with medical nutrition therapy (MNT) in a broader lifestyle modification program. Implementing diabetes-specific MNT in Asia requires high-quality and transparent clinical practice guidelines (CPGs)
\end{abstract}

\section{H.-Y. Su}

Department of Dietetics, Taipei Medical University Hospital,

Taipei, Taiwan

H.-Y. Su

School of Nutrition and Health Sciences,

Taipei Medical University,

Taipei, Taiwan

M.-W. Tsang

Medical and Geriatric Department, United Christian Hospital,

Kwun Tong, Hong Kong

\section{S.-Y. Huang}

School of Nutrition and Health Sciences,

Taipei Medical University,

Taipei, Taiwan

J. I. Mechanick

Division of Endocrinology, Diabetes, and Bone Disease,

Mount Sinai School of Medicine,

New York, NY, USA that are regionally adapted for cultural, ethnic, and socioeconomic factors. Respected CPGs for nutrition and diabetes therapy are available from prestigious medical societies. For cost efficiency and effectiveness, health care authorities can select these CPGs for Asian implementation following abridgement and cultural adaptation that includes: defining nutrition therapy in meaningful ways, selecting lower cutoff values for healthy body mass indices and waist circumferences (WCs), identifying the dietary composition of MNT based on regional availability and preference, and expanding nutrition therapy for concomitant hypertension, dyslipidemia, overweight/obesity, and chronic kidney disease. An international task force of

\section{W. H.-H. Sheu}

Division of Endocrinology and Metabolism,

Department of Medicine, Taichung Veterans General Hospital, Taichung, Taiwan

W. H.-H. Sheu

School of Medicine, National Yang-Ming Medical University, Taipei, Taiwan

W. H.-H. Sheu

College of Medicine, National Defense Medical Center, Taipei, Taiwan

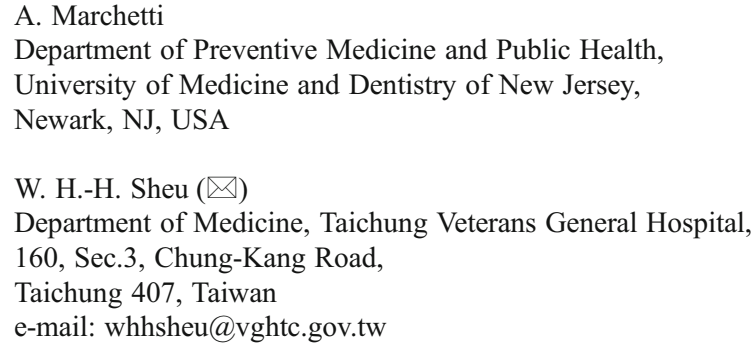


respected health care professionals has contributed to this process. To date, task force members have selected appropriate evidence-based CPGs and simplified them into an algorithm for diabetes-specific nutrition therapy. Following cultural adaptation, Asian and Asian-Indian versions of this algorithmic tool have emerged. The Asian version is presented in this report.

Keywords Asians · Diabetes · Diabetes-specific formula . Medical nutrition therapy

\section{Introduction}

Increased urbanization with attendant lifestyle changes and older populations have led to a marked increase in the incidence and prevalence of type 2 diabetes (T2D) in many Asian countries [1-3]. An estimated $60 \%$ of the global population of people with T2D now resides in Asia [4•], with the largest numbers of afflicted individuals in India and China [3]. Epidemiologic shifts in prevalence rates in Asian countries, which cover Asia continents and several pacific islands, have imposed an enormous burden on their societies, resulting in increased morbidity and mortality among patients who also incur higher health care expenditures.

Unique features of T2D in Asian populations create a complex and challenging management problem. Asian populations are heterogeneous, with different rates of T2D depending on cultural, ethnic, and socioeconomic variances. Asians tend to develop T2D at a younger age, have a lesser degree of diabetes-related obesity, suffer longer from complications, and die earlier compared with other ethnicities [5]. Asians with T2D experience postprandial hyperglycemia more frequently [6•]. Moreover, data consistently demonstrate that Asians with T2D have a higher risk of renal complications compared with patients of European descent [7]. In a large-scale multinational survey, up to $60 \%$ of Asian patients with T2D had albuminuria versus $30-40 \%$ in a comparative Western cohort $[8,9]$. These unique characteristics of T2D in Asians must be considered when selecting therapeutic options and formulating comprehensive management strategies.

To inform management decisions, most affluent countries rely on sophisticated health services and prestigious medical organizations that seek to address important issues in diabetes. Likewise, they have developed tools that assist in standardizing care for diabetes and a host of other diseases and disorders. For example, sophisticated clinical practice guidelines (CPG) now exist for most common medical problems, their diagnosis, and treatment. Such guidelines help physicians make challenging decisions, improving outcomes while controlling costs $[10,11]$. In general, CPGs are useful but also have limitations $[2,11,12]$. Commonly, their recommendations are based on evidence from clinical studies conducted among patients with similar demographics, especially those from the larger more homogeneous segments of their societies. Rarely are recommendations responsive to emergent cultural or social factors, which are usually omitted from CPGs, thus severely limiting their portability [13].

Application of evidence-based recommendations from Western CPGs to Asian patients with T2D represents a quintessential example of this portability shortcoming. Lifestyles, foods, and traditions can vary greatly between Western and Asian peoples. Moreover, the availability of medical resources may be limited compared with Western countries, and routine clinical practices may be divergent. To improve the applicability and transportability of guidelines for lifestyle modification in diabetes, a transcultural task force was assembled, a series of international and regional meetings was convened, and cultural factors that influence the development and progression of T2D, as well as its management, were identified. Thereafter, these factors were incorporated into a master algorithm for diabetes-nutrition therapy that can hopefully be applied globally to help control the worldwide epidemic in cardiometabolic disease.

This paper describes specific task force activities and findings within Asian countries and contributes to our understanding of the human characteristics that influence diets, eating patterns, and lifestyle choices. It also conveys transcultural factors that influence the adaptability of current evidence-based CPGs for diabetes-specific nutrition therapy and the implementation of those guidelines within Asian countries.

\section{Transcultural Factors for Asia}

\section{Assessment of Body Composition and Risk of Disease} Progression

Anthropometric measures - including body mass index (BMI), WC, and waist-to-hip ratio - are used to assess body composition and the risk of $\mathrm{T} 2 \mathrm{D}$ progression across populations. However, determinations may be different for Asians compared with white individuals. For example, optimum cutoff points for obesity vary based on genetic differences between Asians and whites and the heterogeneous nature of various Asian populations. The upper BMI values of $25 \mathrm{~kg} / \mathrm{m}^{2}$ for overweight and $30 \mathrm{~kg} / \mathrm{m}^{2}$ for obese from the World Health Organization (WHO) are too high for Asians according to international consensus [14]. In 2000, the WHO Western Pacific Regional Office proposed a modified upper BMI cutoff value of $23 \mathrm{~kg} / \mathrm{m}^{2}$ for overweight and $25 \mathrm{~kg} / \mathrm{m}^{2}$ for obese in Asian populations [15]. Likewise, the proposed Asian-specific WC cutoff values for central adiposity $(90 \mathrm{~cm}$ for men, $80 \mathrm{~cm}$ for women), which differ from cutoff values for whites (40 inches for men and 35 inches for women) [15], were adopted 
by most Asian countries [16]. In Japan, upper WC cutoff values of $85 \mathrm{~cm}$ for men and $90 \mathrm{~cm}$ for women were recommended based on correlation with $100 \mathrm{~cm}^{2}$ of visceral fat area obtained by computed tomography scan [17]. Within Asian versions of the transcultural algorithm for diabetes-nutrition therapy, these values replace corresponding standards for white patients.

\section{Benefits of Active Lifestyle in Diabetes Management}

Recommendations for the comprehensive management of diabetes encourage patients to maintain an active lifestyle because physical activity and exercise provide many health benefits and facilitate glycemic control [18-21]. A Chinese Da Qing lifestyle study of patients with impaired glucose tolerance demonstrated that lifestyle interventions can prevent the development of T2D and cardiovascular disease (CVD) [22]. In response to these observations, most Asian medical professionals recommend 150 min per week of moderate-intensity exercise for patients with diabetes as part of their comprehensive management [18-21]. This recommendation corresponds to similar guidance for white patients and, therefore, appears unchanged in Asians versions of the diabetes-specific nutrition algorithm.

\section{Appropriate Selection of Diet for Glycemic Control}

Dietary habits and food compositions influence glycemic control, the development and progression of diabetes, and the risk of diabetic complications [23]. Unlike the gradual nutrition transition with large portion and high-energy density [24] that occurred in the United States and most European countries, the nutrition transition in many Asian countries has been rapid [25]. In general, the mean per capita consumption of calories, carbohydrates, protein, and fats is rising as the economies grow plus industrialization with sedentary life pattern [26, 27]. Appropriate dietary education based on individual risk factors such as prediabetes or T2D, cardiometabolic status, medicinal use, and degree of overweight/obesity is needed to facilitate the implementation and acceptance of dietary recommendations. Information about foods with higher glycemic indices (GI) or glycemic loads (GL) should be emphasized, since Asians with T2D are more prone to postprandial hyperglycemia [6•]. For instance, "glutinous" short grain rice is a relatively high glycemic index food [28], and is a popular carbohydrate staple. Replacing or exchanging quantities of this grain with lower GI or GL grains would have salutary effects on overall glycemic control [29].

\section{Medical Nutrition Therapy and Weight Loss in Diabetes} Management

Medical nutrition therapy (MNT) is an important component of any comprehensive management program for prediabetes and diabetes in both Asian and white patients alike. It consists of nutritional assessment and counseling, as well as specific dietary modifications intended to improve glycemic and weight control [30]. Evidence-based research strongly suggests that MNT provided by a registered dietitian who is experienced in the management of diabetes is clinically effective. Incorporating MNT into diabetes-specific nutritional management has been shown to improve glycemic profiles and reduce the risk of disease complications [31]. MNT also can lead to moderate weight reduction that ameliorates insulin resistance, endothelial dysfunction, and dyslipidemias [32-34]. Randomized controlled studies have shown about $1 \%$ reductions in hemoglobin $\mathrm{A}_{1 \mathrm{c}}\left(\mathrm{HbA}_{1 \mathrm{c}}\right)$ in new patients with type 1 diabetes, $2 \%$ reductions in new patients with T2D, and $1 \%$ in patients with $\mathrm{T} 2 \mathrm{D}$ of 4 years average duration [30]. In the initial treatment of T2D, MNT should be combined with physical activity in a lifestyle modification plan for individuals with fasting plasma glucose levels of less than $200 \mathrm{mg} / \mathrm{dL}$. Patients withT2D who cannot achieve acceptable treatment goals or who experience disease progression due to $\beta$-cell failure should intensify lifestyle modification and start prescription medication.

Although several MNT guidelines have arisen from Asian countries (Table 1), the effects of MNT on glycemic control in Asians with T2D are still unclear and require further investigation. However, at least one randomized controlled trial has reported the effectiveness of dietitianled diabetes management on diet and glycemic control in a primary care setting in Taiwan [37]. In that study, patients with $\mathrm{HbA}_{1 \mathrm{c}}$ measurements of $7 \%$ or higher had significantly greater improvements in fasting plasma glucose and $\mathrm{HbA}_{1 \mathrm{c}}$ levels at 1 year than control subjects or interventional subjects with $\mathrm{HbA}_{1 \mathrm{c}}$ levels of less than $7 \%$. The study concluded that diabetes nutrition therapy led by a registered dietitian can help to improve glycemic control in patients with poorly managed T2D in a primary care clinic. These results, coupled with similar findings in related international research reported elsewhere in this journal, have generated a general interest in MNT for Asians and the willingness of Asian task force members to support the nutrition algorithm with regional adaptations for MNT.

Use of Diabetes-Specific Formulas to Facilitate Glycemic Control

Diabetes-specific (glycemia targeted specialized) nutrition formulas are nutrition-rich calorie replacements for normal, overweight, or obese individuals or calorie supplements for underweight individuals with T2D. They are associated with demonstrable benefits in glycemic control parameters. Typically, MNT programs include diabetes-specific formula (DSF) in their armamentariums. In a study involving insulin-treated patients with T2D who received enteral 


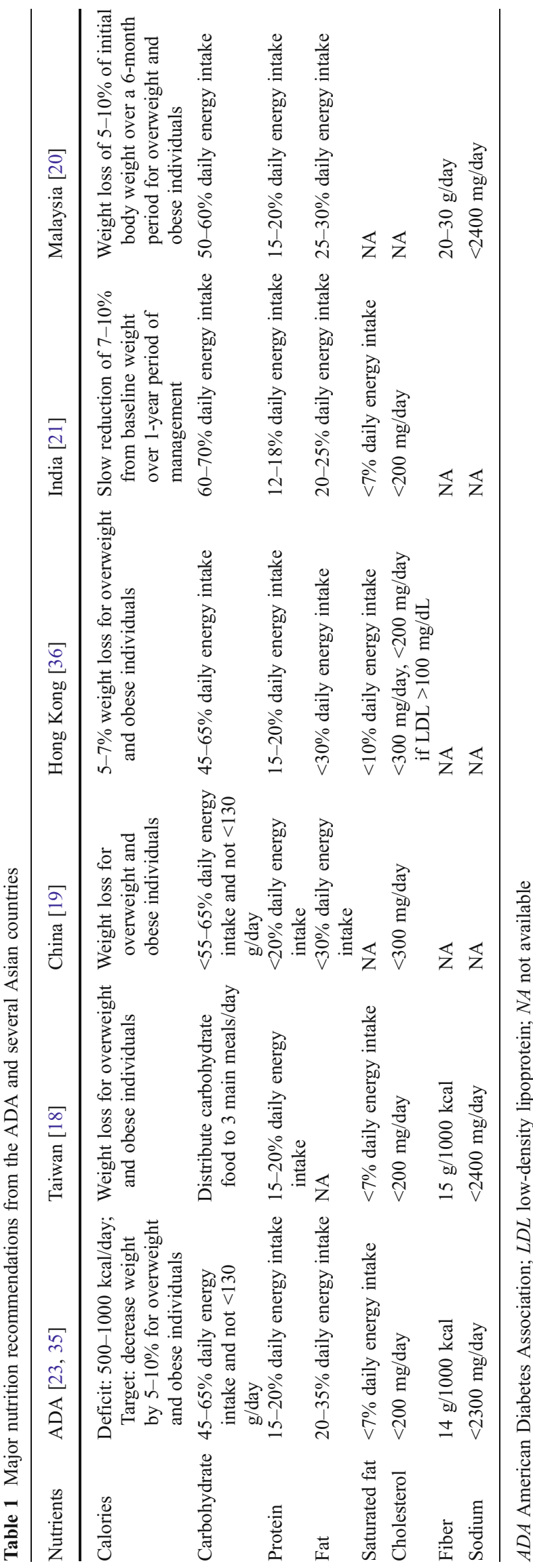

nutrition, the use of a low-carbohydrate, high monounsaturated fatty acid formula improved glycemic control compared with a standard enteral nutrition formula [38]. A more recent study showed that postprandial glucose responses were lower and were maintained during a 4-week trial of DSF in patients with T2D [39•]. Additionally, a systematic review showed that short-term and long-term use of DSF as oral supplementation and enteral nutrition support are associated with improved glycemic control compared with standard formulas [40].

Further research is required to determine if studies conducted in Western populations can be extrapolated to other cultural settings. For example, some Asian subpopulations have lactose intolerance, which might hinder the use of milk-based DSF products [41]. Potential remedies for this problem include exogenous $\beta$-galactosidase, yogurt, and other probiotics that can be ingested for their bacterial lactase activity, and pharmacologic or nonpharmacologic interventions that can help to overcome intestinal malabsorption [42]. Again, further investigation is required.

\section{Bariatric Surgery for Patients with T2D and Obesity}

The International Diabetes Federation (IDF) Taskforce on Epidemiology and Prevention of Diabetes recently announced that certain bariatric surgical procedures can significantly improve glycemic control in severely obese patients with T2D [43]. The IDF recommends the development of national guidelines for bariatric surgery for people with $\mathrm{T} 2 \mathrm{D}$ with a BMI $\geq 35 \mathrm{~kg} / \mathrm{m}^{2}$. For Asians and other ethnicities with increased cardiometabolic risks, intervention may be appropriate at lower BMI (eg, 27.5$32.5 \mathrm{~kg} / \mathrm{m}^{2}$ ). Given the increase in the number of at-risk Asians, there is an imperative to scientifically establish BMI action points and to develop effective plans for their implementation [44].

Nutritional Management of Patients with Comorbid Conditions: Hypertension, Dyslipidemia, and/or Chronic Kidney Disease

The prevalence and awareness of hypertension varies around the world [45]. In Asian countries, an increased incidence of hypertension has been observed [46]. Consequently, the prevalence of hypertension in men is expected to increase to $65.4 \%$ compared with $51.2 \%$ in the rest of the world. Likewise, the prevalence of hypertension is expected to increase rapidly in Asian women following an $81.6 \%$ increase in incidence rates compared with a $54.4 \%$ increase in incidence in the rest of the world.

Hypertension, with or without nephropathy, is more difficult to control in the presence of T2D. The majority of patients with $\mathrm{T} 2 \mathrm{D}$ require two or more drugs to reach 
desired blood pressure targets. As part of overall management, lifestyle modification can be implemented according to the S-ABCDE mnemonic: salt restriction, alcohol limitation, body weight reduction, cessation of smoking, diet adaptation, and exercise adoption [47]. The generally accepted recommended daily intake for sodium is a maximum of $2.4 \mathrm{~g}$ of sodium or $6 \mathrm{~g}$ of sodium chloride. The Dietary Approaches to Stop Hypertension (DASH) diet emphasizes fruits, vegetables, and low-fat dairy products and includes whole grains, poultry, fish, and nuts, as well as reduced fats, red meat, sweets, and sugary drinks [48]. The DASH diet can reduce systolic and diastolic blood pressure by 11.4 and $5.5 \mathrm{~mm} \mathrm{Hg}$, respectively, in hypertensive patients [49]. However, because of its relatively high potassium, phosphorus, and protein content, the DASH diet is not recommended for patients with stage 3 or 4 chronic kidney disease (CKD) with an estimated glomerular filtration rate of less than $60 \mathrm{~mL} / \mathrm{min} / 1.73 \mathrm{~m}^{2}$ [50].

Randomized clinical trials have confirmed the benefits of using statins to reduce low-density lipoprotein cholesterol in preventing CVD. There is strong evidence delineating the pathophysiologic roles of T2D and dyslipidemia in cardiorenal disease and the benefits of lipid-lowering treatments [51]. It is believed that the high rate of CKD with T2D, a close link to CVD, and the benefits of lipid-lowering treatments on renal function are all relevant for cardiometabolic risk reduction and disease management. For patients with CKD and T2D, a limited protein intake is recommended: $0.8-1.0 \mathrm{~g} / \mathrm{kg}$ in stages $1-2$ and less than $0.8 \mathrm{~g} / \mathrm{kg}$ in stage 3 or greater [52]. Although most national guidelines use criteria similar to the Western world for management of dyslipidemia in patients with $\mathrm{T} 2 \mathrm{D}$, there are consistently low rates of lipid-lowering drug use and attainment of treatment goals in Asia [53]. This implementation hindrance resonates with the need for the transculturalization of established CPGs.

\section{Conclusions}

MNT is an essential component in the comprehensive management of prediabetes and T2D. In appropriately selected patients, it precedes the initiation of pharmacologic therapy and is prescribed concomitantly thereafter. Numerous CPGs for diabetes-specific nutrition are available from prestigious medical societies and health care services but have limited portability to Asian countries. However, with rigorous cultural adaptations they can be modified, implemented, and adopted regionally throughout Asia. To achieve these objectives, an international task force developed a transcultural diabetes-specific nutrition algorithm that simplifies complex diabetes guidelines into an easy-to-use format that is adaptable. The Asian adaptation accommodates regional differences in lifestyles, foods, and customs to meet the needs and preferences of afflicted patients. Future efforts for this region will focus on defining additional questions regarding transcultural factors, developing and implementing facile tools that can improve clinical outcomes in a cost-effective manner, and perhaps modulating the health promotion culture so that comprehensive primary prevention strategies can be more successful.

Acknowledgments The authors would like to thank the following additional members of the Task Force for Development of Transcultural Algorithms in Nutrition and Diabetes: Caroline Apovian, MD, Nutrition and Weight Management Center, Boston University School of Medicine, Boston, MA, USA; Alexander Benchimol, MD, Obesity and Eating Disorders Group, State Institute of Diabetes and Endocrinology of Rio de Janeiro, Rio de Janeiro, Brazil; Peter Bisschop, MD, Division of Endocrinology and Metabolism, Academic Medical Center, University of Amsterdam, Amsterdam, The Netherlands; Alexis BolioGalvis, MD, Department of General and Bariatric Surgery and Clinical Nutrition, Hospital Angeles Pedregal; Clinical Nutrition and General Surgery, Facultad Mexicana de Medicina, Universidad La Salle, Mexico City, Mexico; Refaat Hegazi, MD, Research \& Development, Abbott Nutrition, Columbus, OH, USA; David Jenkins, MD, Department of Nutritional Sciences, University of Toronto, Toronto, Ontario, Canada; Enrique Mendoza, MD, University of Panama School of Medicine, Panama City, Panama; Miguel Leon-Sanz, PhD, Service of Endocrinology and Nutrition, University Hospital Doce de Octubre, Madrid, Spain; Patrizio Tatti, PhD, Department of Endocrinology and Diabetology, ASL $\mathrm{RMH}$, Rome, Italy.

Disclosure Conflicts of interest: The development of this article was funded by Abbott Nutrition.

H.-Y. Su: has received financial support from Abbott Nutrition, Pfizer, GlaxoSmithKline, and Bayer for consultancy; M.-W. Tsang: none; S.-Y. Huang: none; J.I. Mechanick: has received financial support for the development of educational presentations from Abbott Nutrition. He has received financial support for consultancy and for writing and reviewing the manuscript from Abbott Nutrition. He has received fees for participation in review activities such as data monitoring boards, statistical analysis, and end point committees from Abbott Nutrition International. He has received funding for travel and accommodations from Abbott Nutrition; W.H-H. Sheu: has received financial support for consultancy from Abbott Nutrition, Pfizer, GlaxoSmithKline, and Bayer; A. Marchetti: has received financial support for research and the development of educational materials from BMS, Abbott Nutrition, Takeda, and Eli Lilly; O. Hamdy: has received financial support for consultancy from Abbott Nutrition. He has received financial support as a speaker for Amylin/Eli Lilly.

\section{References}

Papers of particular interest, published recently, have been highlighted as:

- Of importance

1. Chang CH, Shau WY, Jiang YD, Li HY, Chang TJ, Sheu WH, et al. Type 2 diabetes prevalence and incidence among adults in Taiwan during 1999-2004: a national health insurance data set study. Diabet Med. 2010;27:636-43.

2. International Diabetes Federation. IDF Diabetes Atlas. 2009. http://www.idf.org/diabetesatlas/. Accessed October 102011. 
3. Wild S, Roglic G, Green A, Sicree R, King H. Global prevalence of diabetes: estimates for the year 2000 and projections for 2030 . Diabetes Care. 2004;27:1047-53.

4. - Chan JC, Malik V, Jia W, Kadowaki T, Yajnik CS, Yoon KH, et al. Diabetes in Asia: epidemiology, risk factors, and pathophysiology. JAMA. 2009;301:2129-40. This paper profiled the epidemiology of obesity and T2D in the Asia region.

5. Yoon KH, Lee JH, Kim JW, Cho JH, Choi YH, Ko SH, et al. Epidemic obesity and type 2 diabetes in Asia. Lancet. 2006;368:1681-8.

6. - Wang JS, Tu ST, Lee IT, Lin SD, Lin SY, Su SL, et al. Contribution of postprandial glucose to excess hyperglycaemia in Asian type 2 diabetic patients using continuous glucose monitoring. Diabetes Metab Res Rev. 2011;27:79-84. This paper is important because it highlights the way postprandial hyperglycemia contributes to $\mathrm{Hb} A_{1 c}$ levels.

7. Karter AJ, Ferrara A, Liu JY, Moffet HH, Ackerson LM, Selby JV. Ethnic disparities in diabetic complications in an insured population. JAMA. 2002;287:2519-27.

8. Chiang SC, Lee JK, Chen CH, Chuang LM, Tsan KW, Sheu WH, et al. Justifying the high prevalence of microalbuminuria for type 2 diabetic patients in Taiwan with conditional probability approacha DEMAND II study. J Chin Med Assoc. 2011;74:3-10.

9. Wu AY, Kong NC, de Leon FA, Pan CY, Tai TY, Yeung VT, et al. An alarmingly high prevalence of diabetic nephropathy in Asian type 2 diabetic patients: the MicroAlbuminuria Prevalence (MAP) Study. Diabetologia. 2005;48:17-26.

10. Scalzitti DA. Evidence-based guidelines: application to clinical practice. Phys Ther. 2001;81:1622-8.

11. Woolf SH, Grol R, Hutchinson A, Eccles M, Grimshaw J. Clinical guidelines: potential benefits, limitations, and harms of clinical guidelines. BMJ. 1999;318:527-30.

12. Feder G, Eccles M, Grol R, Griffiths C, Grimshaw J. Clinical guidelines: using clinical guidelines. BMJ. 1999;318:728-30.

13. Problems with Current Practice Guidelines and Quality Improvement (QI) Programs and How to Solve Them. http:// wellness.wikispaces.com/page/pdf/Problems+with+Current+ Practice + Guidelines + and + Quality + Improvement $+\% 28 \mathrm{QI} \%$ 29+Programs+and+How+to+Solve+Them. Accessed November 92011.

14. WHO Expert Consultation. Appropriate body-mass index for Asian populations and its implications for policy and intervention strategies. Lancet. 2004;363:157-63.

15. International Diabetes Institute. The Asia-Pacific perspective: Redefining obesity and its treatment. 2000. http://www.diabetes. com.au/pdf/obesity_report.pdf. Accessed November 92011.

16. Tan CE, Ma S, Wai D, Chew SK, Tai ES. Can we apply the National Cholesterol Education Program Adult Treatment Panel definition of the metabolic syndrome to Asians? Diabetes Care. 2004;27:1182-6.

17. Examination Committee of Criteria for 'Obesity Disease' in Japan. Japan Society for the Study of Obesity. New criteria for 'obesity disease' in Japan. Circ J. 2002;66:987-92.

18. Diabetes Association of the Republic of China. Diabetes Clinical Practice Guideline. 2010. http://www.endo-dm.org.tw/dia/dia bookidx.asp Accessed October 102011.

19. Chinese Diabetes Society. China medical nutrition therapy guideline for diabetes. 2010. http://cdschina.org/. Accessed October 102011.

20. Malaysian Endocrine \& Metabolic Society, Ministry of Health (Malaysia), Academy of Medicine Malaysia, Persatuan Diabetes Malaysia. Management of Type 2 Diabetes Mellitus. 2009. http:// www.scribd.com/doc/18473103/Management-of-Type-2-DiabetesMellitus-4th-Edition-2009. Accessed October 102011.

21. DiabetesIndia.com. The Management of Type 2 Diabetes: Academic Care to Clinical Guidelines 2009. 2009. http://www. diabetesindia.com/diabetes/site_consensus.htm. Accessed October 102011.
22. Li G, Zhang P, Wang J, Gregg EW, Yang W, Gong Q, et al. The long-term effect of lifestyle interventions to prevent diabetes in the China Da Qing Diabetes Prevention Study: a 20-year follow-up study. Lancet. 2008;371:1783-9.

23. Bantle JP, Wylie-Rosett J, Albright AL, Apovian CM, Clark NG, Franz MJ, et al. Nutrition recommendations and interventions for diabetes: a position statement of the American Diabetes Association. Diabetes Care. 2008;31 Suppl 1:S61-78.

24. Astrup A, Dyerberg J, Selleck M, Stender S. Nutrition transition and its relationship to the development of obesity and related chronic diseases. Obes Rev. 2008;9 Suppl 1:48-52.

25. Kim S, Moon S, Popkin BM. The nutrition transition in South Korea. Am J Clin Nutr. 2000;71:44-53.

26. Drewnowski A, Popkin BM. The nutrition transition: new trends in the global diet. Nutr Rev. 1997;55:31-43.

27. Popkin BM. The nutrition transition and its health implications in lower-income countries. Public Health Nutr. 1998;1:5-21.

28. Jenkins DJ, Wolever TM, Taylor RH, Barker H, Fielden H, Baldwin JM, et al. Glycemic index of foods: a physiological basis for carbohydrate exchange. Am J Clin Nutr. 1981;34:362-6.

29. Chan EM, Cheng WM, Tiu SC, Wong LL. Postprandial glucose response to Chinese foods in patients with type 2 diabetes. J Am Diet Assoc. 2004;104:1854-8.

30. Pastors JG, Warshaw H, Daly A, Franz M, Kulkarni K. The evidence for the effectiveness of medical nutrition therapy in diabetes management. Diabetes Care. 2002;25:608-13.

31. Morris SF, Wylie-Rosett J. Medical nutrition therapy: a key to diabetes management and prevention. Clinical Diabetes. 2010;28:12-8.

32. Lang HF, Chou CY, Sheu WH, Lin JY. Weight loss increased serum adiponectin but decreased lipid levels in obese subjects whose body mass index was lower than $30 \mathrm{~kg} / \mathrm{m}(2)$. Nutr Res. 2011:31:378-86.

33. Liang KW, Lee WJ, Lee IT, Lee WL, Lin SY, Hsu SL, et al. Persistent elevation of paraoxonase-1 specific enzyme activity after weight reduction in obese non-diabetic men with metabolic syndrome. Clin Chim Acta. 2011;412:1835-41.

34. Sheu WH, Chang TM, Lee WJ, Ou HC, Wu CM, Tseng LN, et al. Effect of weight loss on proinflammatory state of mononuclear cells in obese women. Obesity (Silver Spring). 2008;16:1033-8.

35. American Diabetes Association. Nutrition recommendations and interventions for diabetes: a position statement by the American Diabetes Association. Diabetes Care. 2007;30 Suppl 1:S48-65.

36. Department of Health Professional Development and Quality Assurance Clinical Audit and Guideline Working Group. Type II diabetes treatment guidelines. 2010. http://www.pdqa.gov.hk/ tc chi/primarycare/clinical/files/DM3.pdf. Accessed October 10 2011.

37. Huang MC, Hsu CC, Wang HS, Shin SJ. Prospective randomized controlled trial to evaluate effectiveness of registered dietitian-led diabetes management on glycemic and diet control in a primary care setting in Taiwan. Diabetes Care. 2010;33:233-9.

38. Pohl M, Mayr P, Mertl-Roetzer M, Lauster F, Lerch M, Eriksen J, et al. Glycaemic control in type II diabetic tube-fed patients with a new enteral formula low in carbohydrates and high in monounsaturated fatty acids: a randomised controlled trial. Eur J Clin Nutr. 2005;59:1221-32.

39. - Lansink M, van Laere KM, Vendrig L, Rutten GE. Lower postprandial glucose responses at baseline and after 4 weeks use of a diabetes-specific formula in diabetes type 2 patients. Diabetes Res Clin Pract. 2011;93:421-9. This paper demonstrated that DSF could lower postprandial glucose in patients with T2D.

40. Elia M, Ceriello A, Laube H, Sinclair AJ, Engfer M, Stratton RJ. Enteral nutritional support and use of diabetes-specific formulas for patients with diabetes: a systematic review and meta-analysis. Diabetes Care. 2005;28:2267-79. 
41. Suchy FJ, Brannon PM, Carpenter TO, Fernandez JR, Gilsanz V, Gould JB, et al. National Institutes of Health Consensus Development Conference: lactose intolerance and health. Ann Intern Med. 2010;152:792-6.

42. Shaukat A, Levitt MD, Taylor BC, MacDonald R, Shamliyan TA, Kane RL, et al. Systematic review: effective management strategies for lactose intolerance. Ann Intern Med. 2010;152:797-803.

43. Dixon JB, Zimmet P, Alberti KG, Rubino F. Bariatric surgery: an IDF statement for obese Type 2 diabetes. Diabet Med. 2011;28:628-42. A taskforce report of bariatric surgery for obese type 2 diabetes.

44. Lakdawala M, Bhasker A. Asian Consensus Meeting on Metabolic Surgery (ACMOMS). Report: Asian Consensus Meeting on Metabolic Surgery. Recommendations for the use of Bariatric and Gastrointestinal Metabolic Surgery for Treatment of Obesity and Type II Diabetes Mellitus in the Asian Population: August 9th and 10th, 2008, Trivandrum, India. Obes Surg. 2010;20:929-36.

45. Kearney PM, Whelton M, Reynolds K, Whelton PK, He J. Worldwide prevalence of hypertension: a systematic review. J Hypertens. 2004;22:11-9.

46. Kearney PM, Whelton M, Reynolds K, Muntner P, Whelton PK, He J. Global burden of hypertension: analysis of worldwide data. Lancet. 2005;365:217-23.

47. Chiang CE, Wang TD, Li YH, Lin TH, Chien KL, Yeh HI, et al. 2010 guidelines of the Taiwan Society of Cardiology for the management of hypertension. J Formos Med Assoc. 2010;109:740 73.

48. Appel LJ, Moore TJ, Obarzanek E, Vollmer WM, Svetkey LP, Sacks FM, et al. A clinical trial of the effects of dietary patterns on blood pressure. DASH Collaborative Research Group. N Engl J Med. 1997;336:1117-24.

49. Neter JE, Stam BE, Kok FJ, Grobbee DE, Geleijnse JM. Influence of weight reduction on blood pressure: a meta-analysis of randomized controlled trials. Hypertension. 2003;42:878-84.

50. Kidney Disease Outcomes Quality Initiative (K/DOQI). K/DOQI clinical practice guidelines on hypertension and antihypertensive agents in chronic kidney disease. Am J Kidney Dis. 2004;43:S1290.

51. Chan JC, Chan SP, Deerochanawong C, Go RT, Lee KO, Ma RC, et al. Diabetic dyslipidaemia in Asian populations in the Western Pacific Region: What we know and don't know. Diabetes Res Clin Pract. 2011;94:1-13.

52. National Kidney Foundation. KDOQI Clinical Practice Guidelines and Clinical Practice Recommendations for Diabetes and Chronic Kidney Disease. 2007. http://www.kidney.org/professionals/ KDOQI/guideline_diabetes/. Accessed October 102011.

53. Park JE, Chiang CE, Munawar M, Pham GK, Sukonthasarn A, Aquino AR, et al. Lipid-lowering treatment in hypercholesterolaemic patients: the CEPHEUS Pan-Asian survey. Eur J Cardiovasc Prev Rehabil. 2011. 